\title{
A DECISION SUPPORT MODEL FOR CIVIL ENGINEERING PROJECTS BASED ON MULTI-CRITERIA AND VARIOUS DATA
}

\author{
Usama H. ISSA ${ }^{1,2}$, Yehia H. MIKY ${ }^{3,4}$, Fam F. ABDEL-MALAK ${ }^{4}$ \\ ${ }^{1}$ Civil Engineering Department, College of Engineering, Taif University, Saudi Arabia \\ ${ }^{2}$ Civil Engineering Department, Faculty of Engineering, Minia University, Egypt \\ ${ }^{3}$ Geomatics Department, Faculty of Environmental Design, King Abdul-Aziz University, Saudi Arabia \\ ${ }^{4}$ Civil Engineering Department, Faculty of Engineering, Aswan University, Egypt
}

Received 09 July 2018; accepted 08 November 2018

\begin{abstract}
This paper develops a model, introduced in software, namely Multi-Criteria Decision-Making Model (MCDMM). The model helps decision makers selecting the most suitable alternative based on the customer requirements and preferences. Analytic Hierarchy Process (AHP) and Fuzzy Technique for Order of Preference by Similarity to Ideal Solution (Fuzzy TOPSIS) form a package that covers most available data types in construction projects. In MCDMM, AHP produces criteria relative weights according to their influence on the discussed problem, while Fuzzy TOPSIS is applied to rank the available alternatives. The model consists of two modules, first one uses AHP only to deal with precise, qualitative alongside quantitative data, while the other module combines AHP with Fuzzy TOPSIS due to the importance of linguistic variables to cover undocumented data. MCDMM is verified using two real case studies. The model is applied to a real case project for constructing solar power plants at Saudi Arabia. A decision required to select the most suitable surveying technique for producing Digital Terrain Model (DTM) among four alternatives (Total Station, Remote Sensing, Photogrammetry, and Global Positioning Systems). This issue is studied and key points are identified for prioritizing among them. Total Station is selected based on the model results.
\end{abstract}

Keywords: multi-criteria decision-making, AHP, Fuzzy TOPSIS, civil engineering projects, solar power plants, surveying techniques.

\section{Introduction}

There are always several alternative behavior patterns to select from them, which can be the best solution to a certain problem. Decision Making (DM) is to make a selection among the alternative behavior patterns to reach a goal and to fulfill a purpose (Forman \& Selly, 2001). Stakeholders and project managers should always make decisions in all stages of Civil Engineering Projects (CEPs) execution; starting from the design stage; passing by bidding process; reaching the closing stage of the project (Abdel-malak, Issa, Miky, \& Osman, 2017). In addition, Multi-Criteria Decision-Making (MCDM) in CEPs is a complicated task due to nature of conflicting between different alternatives and criteria.

CEPs are characterized by specific features and conflicting criteria through all stages of the projects, as well as, they need improving the quality and minimizing costs. Therefore, DM techniques are considered very important and should be implemented when dealing with such projects. DM techniques cover many problems associated to CEPs such as selecting the contractors, outsourcing consultancy, material suppliers, and design alternatives. It can be supportive to determine the best region to execute a national construction project like a nuclear power plant (Erdoğan \& Kaya, 2016). MCDM can be regarded obviously in the aspects of material selection (Jahan, Edwards, \& Bahraminasab, 2016), construction and demolition wastes management (Zyoud, Kaufmann, Shaheen, Samhan, \& Fuchs-Hanusch, 2016), selecting ventilation system for buildings (Alwetaishi, Gadi, \& Issa, 2017), and picking the best technique of repairing and strengthening of different construction elements (Hassan \& Issa, 2015). Besides other none neglecting aspects include planning and construction of infrastructure (El Chanati, El-Abbasy, Mosleh, \& Senouci, 2016), and materials suppliers selection (Bruno, Esposito, Genovese, \& Simpson, 2016; Plebankiewicz \& Kubek, 2016).

*Corresponding author. E-mail: fam.fahmy@aswu.edu.eg 
The problems face all project managers in different CEPs are the lack of data, the undocumented data concerns previous projects as well as the absence of suitable software, in which is helpful, available, easy to use, and flexible to deal with different types of data. The construction community needs software that deals with wide range of data, reduces the uncertainty of available data, taking into consideration more than one weighted source of data. From a decision maker's point of view, the best alternative to be selected is the one that maximizes the benefit criteria and minimizes the cost criteria. Therefore, this research develops a new model that can deal with different types of data, using two modules, and covers the undocumented previous experiences about preceding projects with the help of linguistic variables. The software can help users in the practical applications of the proposed model.

\section{Methodology and techniques}

There are many MCDM techniques but while dealing with CEPs there is a need for simple techniques to be applied that combine both simplicity in structure and complicity in dealing with complex problems and vague data. The issue of choosing techniques, which are appropriate to deal with CEPs features and problems, is investigated in details by authors in a previous research (Abdel-malak et al., 2017). According to the previous work of the research team, AHP and Fuzzy TOPSIS are proposed for forming a package that covers most available data types in CEPs. AHP is used to produce the criteria relative weights according their influence to the discussed problem. While, Fuzzy TOPSIS is applied in order to rank the available alternatives.

So, the proposed model is based on the techniques; AHP and Fuzzy TOPSIS. The proposed model, namely MCDMM, utilizes the Visual Studio Program package as the main programming tool.

The developed model is verified using two real case studies. The model is applied to solve a MCDM problem in a real project at Saudi Arabia. A decision required to select the most suitable surveying technique or instrument in order to produce the DTM. This issue is studied and key points are identified for comparing among four alternatives through five criteria to select the best one. Furthermore, a sensitivity analysis is prepared to indicate effects of different criteria weights on ranking results to present the robustness or sensitiveness of the ranking results versus the relative importance of criteria.

\section{Selecting AHP and Fuzzy TOPSIS}

AHP and Fuzzy TOPSIS are picked up due to their ability to deal with different types and wide ranges of data related to various applications to CEPs. Besides, they can deal with a lot of alternatives, criteria, and factors affecting the decisions. The results from previous research (Abdel-malak et al., 2017) indicated that AHP has a structure, which simplifies complicated problems, while Fuzzy
TOPSIS uses the advantages of linguistic variables to solve the issue of undocumented data and ill-defined problems. Furthermore, AHP is a simple technique that depends on pairwise comparisons of factors and natural attributes, besides it is preferable for widely spread hierarchies. On the other hand, Fuzzy TOPSIS needs more information but works well for the one-tier decision tree as well as it shows more flexibility to work in fuzzy environments. Although other techniques have some common features with the applied ones, AHP and Fuzzy TOPSIS super-pass them with their ability to be integrated and introduced as software (Karahalios, 2017). In addition, Fuzzy TOPSIS ranks alternatives by measuring their relative distances to the Positive Ideal Solutions (PISs) and the Negative Ideal Solutions (NISs), but AHP employs a ratio scale to elicit pairwise comparisons for alternatives and criteria. The two techniques proved to have the facility to be integrated and combined in a new model to support most of the decisions required in CEPs (Abdel-malak et al., 2017).

\subsection{Overview of AHP}

AHP, developed by Saaty (1980), addresses how to determine the relative importance of asset of activities in a MCDM problem. The process makes it possible to integrate judgments on intangible qualitative criteria alongside tangible quantitative criteria. Most of us have difficulty examining even a few ideas at a time. Individuals need instead to organize their problems in a complex structure which allows them to think about them one or two at a time. They need an approach that is conceptually simple so that can be used easily and, at the same time, to be strong enough to handle real world decisions and complexities (Ebrahimnejad, Gitinavard, \& Sohrabvandi, 2017). Here comes the importance of AHP, which based on three procedures (Albayrak \& Erensal, 2004):

- First, structure of the model (Decomposition);

- Second, comparative judgment of alternatives and criteria;

- Third, synthesis of priorities.

In the first step, AHP breaks down a complex MCDM problem into a hierarchy of interrelated elements (criteria, decision alternatives). With AHP, the objectives, criteria, and alternatives are arranged in a hierarchical structure similar to a family tree (Albayrak \& Erensal, 2004).

The second step, once the problem has been decomposed and hierarchy is constructed, comparative judgment procedure starts in order to determine the relative importance of the criteria within the level. In each level, the criteria are compared pairwise according to their levels of influence and based on the specified criteria at the higher level. Pairwise comparisons are based on a standardized scale of nine levels. The nine-point scale can be defined as: 1 refers to "equal importance", 3 refers to "slightly more important", 5 refers to "much more important", 7 refers to "highly more important", and 9 refers to "extremely more important" (Alwetaishi et al., 2017). 
The result of pairwise comparison on $\mathrm{n}$ criteria can summarize in $[X]_{(n \times n)}$ evaluation matrix as shown in Eqn (1):

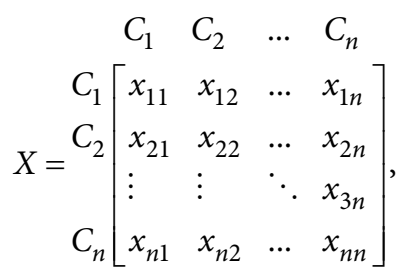

where: $c_{j}=1,2,3, \ldots, n$-is the set of criteria; $x_{i j}(i j=1,2,3, \ldots, n)-$ is the quotient of weight of the criteria; $x_{i j}=1 ; x_{j i}=1 / x_{i j}$; $x_{i j} \neq 0$.

Third step, the subsequent step following the dual comparison matrices is the calculation of the eigenvector showing the importance of each element in the relevant matrix in relation to the others (Albayrak \& Erensal, 2004). The percentage importance distribution of criteria is calculatedas follows in Eqns (2)-(3):

$$
\begin{aligned}
& b_{i j}=\frac{x_{i j}}{\sum_{i=1}^{n} x_{i j}} ; \\
& w_{i}=\frac{\sum_{j=1}^{n} b_{i j}}{n},
\end{aligned}
$$

where: $b_{i j}-$ is the normalized matrices values; $\left[w_{i}\right]_{n \times 1}-$ is the percentage importance distribution of criteria; $n-$ is number of criteria.

Fourth step, Consistency Ratio $(C R)$ is checked for each comparison matrix not exceeding 0.10 at maximum. $C R$ higher than 0.10 shows an inconsistency in the judgments of the decision maker. In this case, the judgments should be improved. To obtain the $C R$ value, Eqns (4) and (5) are calculated:

$$
\begin{aligned}
& {\left[D_{i}\right]_{n^{*} 1}=\left[x_{i j}\right]_{n^{*} n} *\left[w_{i}\right]_{n^{*} 1} ;} \\
& \lambda_{\max }=\frac{\sum_{i=1}^{n} \frac{d_{i}}{w_{i}}}{n},
\end{aligned}
$$

where: $\lambda_{\max }-$ is the biggest eigenvector of the matrix; $\left[D_{i}\right]_{n \times 1}-$ is the weighted matrix.

Another value needed to calculate $C R$ is Random In$\operatorname{dex}(R I)$. The data including the RI values, which consist of constant numbers and are determined according to the $N$ value, are given in Table 1 (Özat, 2013). The calculation of $\mathrm{CR}$ value in line with this information is specified in Eqn (6):

$$
C R=\frac{\lambda_{\max }-n}{(n-1) \star R I}
$$

where: $C R$ - is the consistency ratio; $\lambda_{\max }-$ is the biggest eigenvector of the matrix; $R I$ - is random index; $n-$ is number of criteria.

Table 1. Random index data (Özat, 2013)

\begin{tabular}{|c|c|c|c|c|c|c|c|c|c|c|}
\hline $\mathrm{N}$ & 1 & 2 & 3 & 4 & 5 & 6 & 7 & 8 & 9 & 10 \\
\hline R.I & 0 & 0 & 0.58 & 0.90 & 1.12 & 1.24 & 1.32 & 1.41 & 1.45 & 1.49 \\
\hline
\end{tabular}

\subsection{Overview of TOPSIS}

TOPSIS method is developed by Hwang and Yoon in 1981 (Zyoud et al., 2016) for the first time for solving the MCDM problem. In general, it is based on the principle that the selected alternative should be close to the PISs and far from the NISs as much as possible (Abdel-malak et al., 2017). PISs are defined as the solutions maximizing the benefits criteria while minimizing the harm criteria whereas NISs can be identified as the solution maximizing the harm criteria while minimizing the benefit criteria (Wang \& Lee, 2007). This concept has been widely used in various MCDM situations for solving practical decision problems. The reasons for selecting TOPSIS can be summarized as follows (Karahalios, 2017):

- It is a sound logic that represents the rationale of human choice;

- It is regarded as a unique visualization of the alternatives on a polyhedron;

- It represents a scalar value that accounts for the best and worst alternative choices simultaneously;

- It provides a simple computation process that can be easily programmed into a spread sheet; and

- Its ability to measure the relative performance of the decision alternatives in a simple mathematical form.

On the other hand, precise numbers are used in the performance evaluations and significance weights of the criteria. But, opinions of people including their selection decisions are typically ambiguous and their preferences cannot be predicted with precise numerical values. Thus, precise numbers are insufficient to model the real life conditions which raise the need for a theory to be combined with TOPSIS in order to deal with such problems. Consequently, there is a need for applying fuzzy theories to deal with uncertainty based on the respective characteristics of the investigated issue (Gitinavard, Pishvaee, \& Jalalvand, 2017).

\subsection{Addressing uncertainty in DM}

Mainly, there are four research methods employed for the investigation of uncertain systems including: Probability and statistics, Grey set theory, Fuzzy sets theory and Rough set theory. Each theory has respective characteristics that deal with different kinds of uncertainty (Gitinavard et al., 2017).

As an example, the focus of Grey systems theory is on the uncertainty problems of small samples and poor information that are difficult for probability to handle. Furthermore, Grey set theory emphasizes the investigation of such objects that process clear extension and unclear intension. While fuzzy sets emphasizes on the investigation of problems with cognitive uncertainty, where the research objects possess the characteristic of clear intension and unclear extension (Mousavi, Gitinavard, \& Siadat, 2014). Continuously, rough set theory deals with rough non-overlapping class and rough concepts, which signify the indiscernibility between objects. The object is approximated by both the lower approximation and the upper approximation. The redundancy can be reduced by algorithm of attribute 
reduction, which make pattern discovery possible from the data which may be blurred by too much detail $(\mathrm{Pa}$ checo et al., 2017). Finally, for the kind of problem of cognitive uncertainty with clear intension and unclear extension, like ones related to CEPs, the situation is dealt with in Fuzzy Sets by making use of experience and the so-called membership function or linguistic variables.

Furthermore, one of the efficient extensions of Fuzzy set theory is Hesitant Fuzzy Sets (HFSs) that have been first introduced by Torra and Narukawa (Mousavi et al., 2014). HFSs are utilized when membership degrees of an element should be expressed as a set. For this reason, decision makers could manage the hesitant situation by assigning their opinions under a set. Mousavi et al. (2014) presented HFSs with AHP method to be applied for DM problems under uncertainty. Another extension of Fuzzy sets theory is the Interval-Valued Hesitant Fuzzy Sets (IVHFSs). In IVHFSs, the preferences experts' judgments have been expressed by linguistic variables which transformed to interval-valued hesitant fuzzy element. Tavakkoli-Moghaddam, Gitinavard, Mousavi, and Siadat (2015) presented a new TOPSIS method based on IVHFSs information to compute the criteria weights. Also, Triangular Fuzzy Numbers (TFNs) are proposed as an extension of Fuzzy Sets Theory (TavakkoliMoghaddam et al., 2015).

However, the reason for using TFNs is that it is intuitively easy for the decision-makers to use and calculate. In addition, modeling using TFNs has proven to be an effective way for formulating decision problems where the information available is subjective and imprecise (Abdelmalak et al., 2017). In practical applications, the triangular form of the membership function is used most often for representing fuzzy numbers. According to the aforementioned literature, TFNs is adopted in this research as it uses the advantage of the linguistic variable instead of precise values to recover the undocumented data and ill-defined problems. Furthermore, most of the studies use the TFNs for addressing the uncertainty of the available data (Samuel, Asogbon, Sangaiah, Fang, \& Li, 2017). In the following, some basic important definitions of TFNs are given as follow (Torfi \& Rashidi, 2011; Abdel-malak et al., 2017):

A TFN (a) can be defined by a triplet $\left(a_{1}, a_{2}, a_{3}\right)$, the membership function $\mu_{a}(x)$ is defined as shown in Eqn (7):

$$
\mu_{a}(x)=\left\{\begin{array}{ll}
0, & x<a_{1} \\
\frac{x-a_{1}}{a_{2}-a_{1}}, & a_{1} \leq x \leq a_{2} \\
\frac{x-a_{3}}{a_{2}-a_{3}}, & a_{2} \leq x \leq a_{3} \\
0, & x>a_{3}
\end{array} .\right.
$$

Let $\left(a_{1}, a_{2}, a_{3}\right)$ and $\left(b_{1}, b_{2}, b_{3}\right)$ be two TFNs, then the vertex method is defined to calculate the distance between them as shown in Eqn (8):

$$
d \cdot(\sim a ; \sim b)=\sqrt{\frac{1}{3}\left[\left(a_{1}-b_{1}\right)^{2}+\left(a_{2}-b_{2}\right)^{2}+\left(a_{3}-b_{3}\right)^{2}\right]} \cdot(8)
$$

\section{MCDMM description}

One of the main objectives of this research is developing a model that contains two modules and introduced in software namely MCDMM. It is produced to help decision makers and construction project managers to choose the most appropriate alternative based on the customer requirements and preferences.

This model is designed to overcome some serious problems face the project managers, stakeholders, project owners, and every participant in CEPs. Those problems include insufficient data, the uncertainty of the available data, conflicting factors affecting the choices, and the need to solve too many problems in limited time. The model's design focuses on delivering simple, easy to use, saving time and effort software besides accurate results, based on the customer requirements and preferences through a wide range of criteria and sub-criteria. The decision makers can find a suitable module from the two proposed modules to deal with the available data whatever the data is sufficient or less information concerning the problem are gathered.

As explained previously, MCDMM is based on two of the most used DM techniques, which are AHP and Fuzzy TOPSIS. A wide range of data can be included in the model application. So, one of the modules uses the AHP only to deal with precise, intangible qualitative alongside tangible quantitative data, while the other module combines the AHP with Fuzzy TOPSIS due to the importance of linguistic variables to cover undocumented data and manage data from field surveys.

One of the main contributions of the proposed model, MCDMM, is the ability to deal with uncertainty related to CEPs. The model mitigates or addresses the uncertainty applying one or more of the following features:

- MCDMM check the consistency of all defined values, in each step of the model, to check the expert ability to deal with the discussed problem.

- The model adopts two different fuzzy membership functions to replace precise numbers with linguistic variables on judgments on the discussed problems.

- MCDMM improves the uncertainty of the gathered data by taking into consideration more than one weighted source related to the discussed problem.

- The proposed model deals with various data types whether precise intangible qualitative beside tangible quantitative data or vague data from field surveys through its two modules.

The formulation of the model is illustrated in a flow chart as shown in Figure 1. The model offers the user to select from the following two modules:

1. Module (1) applies AHP technique only.

2. Module (2) applies AHP and Fuzzy TOPSIS.

\subsection{Description of module (1)}

Module (1) is based on AHP technique only to help decision makers reach a rational ranking order of alternatives using less information and spending less time. AHP 


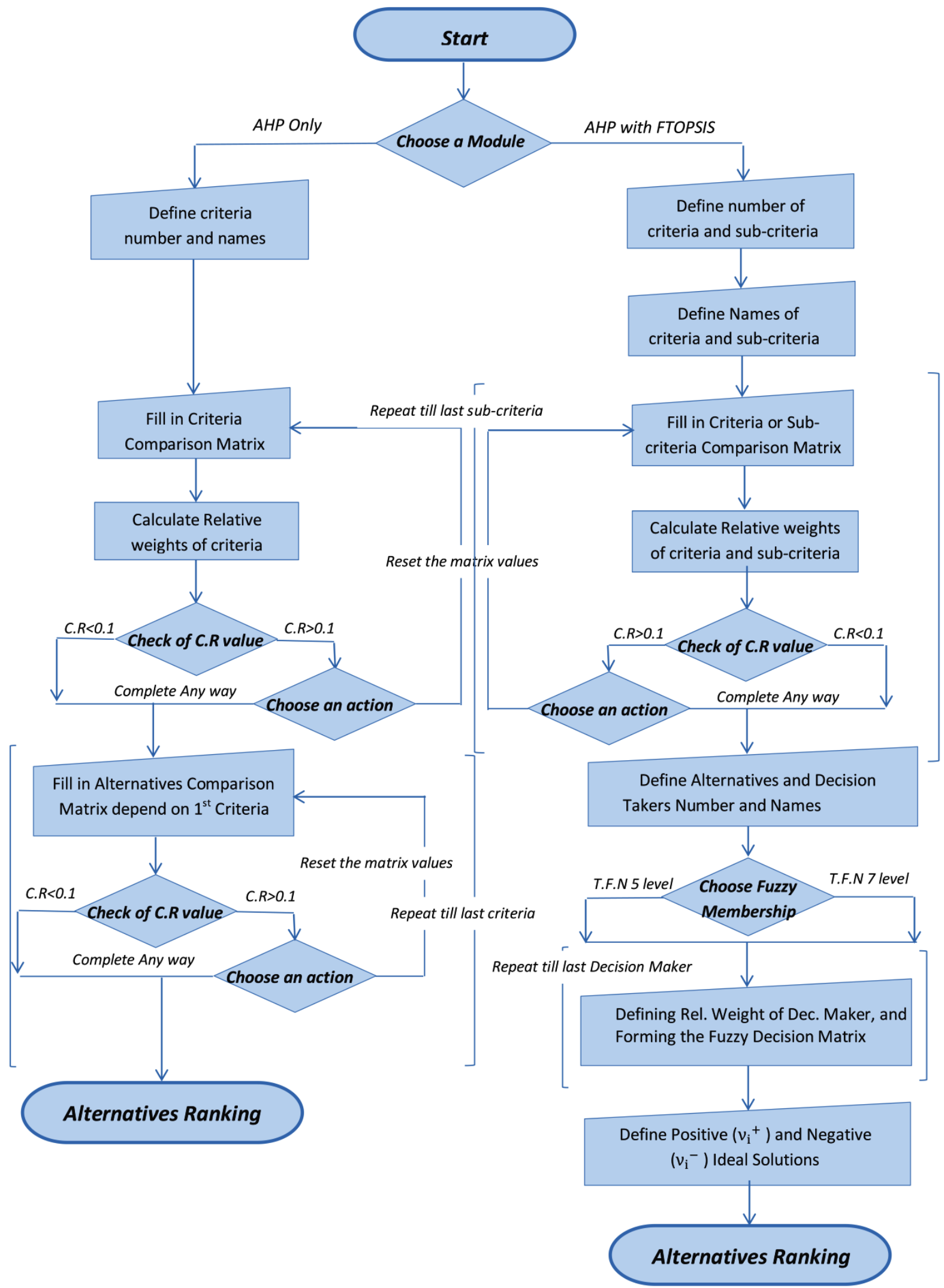

Figure 1. Flowchart of the proposed model 
is popular because pairwise comparisons of factors and attributes come naturally, and dividing a DM problem appears easy.

Users of this module first decompose their decision problem into a hierarchy of more easily comprehended sub-problems, each of which can be analysed independently. A hierarchy has three levels: the overall goal of the problem at the top, multiple criteria that define alternatives in the middle, and decision alternatives at the bottom. The procedures of this module, shown in Figure 2, can be summarized as follows:

1. The user defines the overall goal, number of affecting criteria, and their names.

2. The pairwise comparison matrix of criteria is formed using the values defined in Table 1 . Then, the relative weights of the criteria are calculated $[W]_{n \times 1}$, and $C R$ value is checked to be less than 0.10 if not; the user has to edit the comparison matrix values or choose to complete with the calculated values.

3. Decision makers define number and names of the alternatives to be ranked.

4. In the next level in the hierarchy, pairwise comparison matrices of the alternatives based on one criterion every time are defined.

5. The outputs of this step are $N$ vectors based on $N$ criteria for the given alternatives. Each vector represents the relative weights of the alternatives based on one criterion.

6. By assembling all the calculated vectors, a new matrix $[R]_{m \times n}$ is formed, where $m$ is the total number of alternatives and $n$ is the total number of criteria.

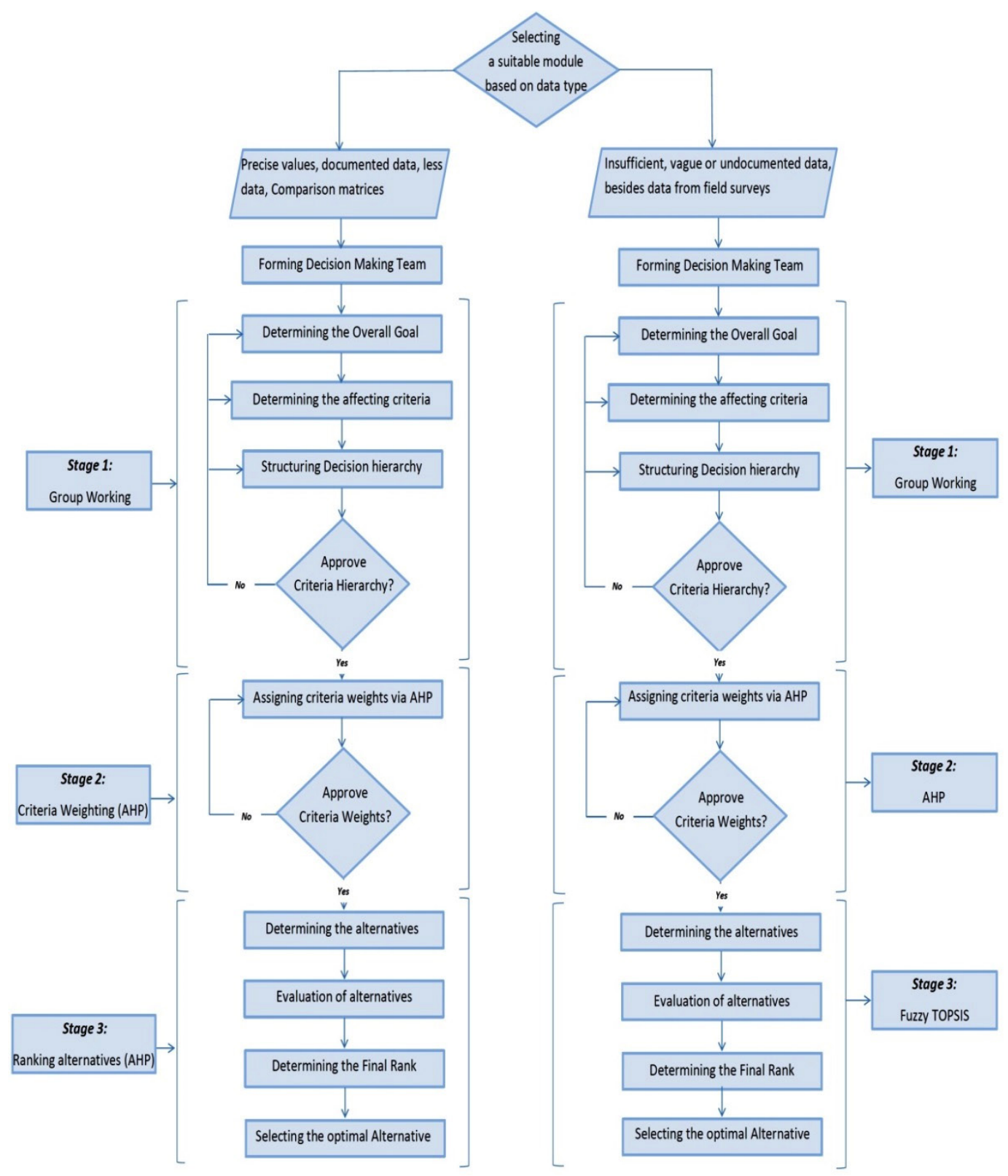

Figure 2. Stages of solving MCDM problem using the proposed model 
7. To get the final alternatives ranking, both of matrix $[W]_{n \times 1}$ and $[R]_{m \times n}$ are multiplied as shown in Eqn (9):

$$
[F]_{m \times 1}=[R]_{m \times n} *[W]_{n \times 1},
$$

where $[F]_{m \times 1}-$ is final alternatives ranking.

\subsection{Description of module (2)}

If the project managers face the problem of insufficient, vague or undocumented data related to the defined problem, they can overcome these problems using the linguistic variables to compare different alternatives. So, module (2) is regarded as a good tool to deal with this type of problems. This module is designed in three stages as shown in Figure 3.

The first stage is breaking down a complex MCDM problem into a hierarchy of interrelated elements. The objectives, criteria, and alternatives are arranged in a hierarchical structure similar to a family tree.

The second stage is determining the relative importance for the criteria within the level and the sub-criteria in the level below using equations from Eqn (1) to Eqn (6).
The third stage is applying Fuzzy TOPSIS to rank the given alternatives according to the distances to positiveideal $\left(v_{i}^{+}\right)$and negative ideal $\left(v_{i}^{-}\right)$solutions as described in next paragraphs.

After calculating both criteria and sub-criteria relative weights using AHP technique, each sub-criteria weight is multiplied in the criteria weight at the above level in order to normalize the calculated weights of sub-criteria. Then, the number of alternatives is defined.

\section{Forming the fuzzy decision matrix}

After defining the available alternatives, the stage of forming the comparison matrix of the defined alternatives against the affecting criteria and sub-criteria is coming to reach the desired ranking of alternatives. According to the available data, the decision makers have the choice to select one of the following fuzzy membership functions:

- TFNs "7" levels as shown in Figure 3.

- TFNs " 5 " levels as shown in Figure 4.

The step of forming the fuzzy decision matrix depends on the number of decision makers participating in this problem and the weight of each one based on his / her experience related to the discussed problem. This weight represents how reliable the choices are to reach more rational and accurate results.

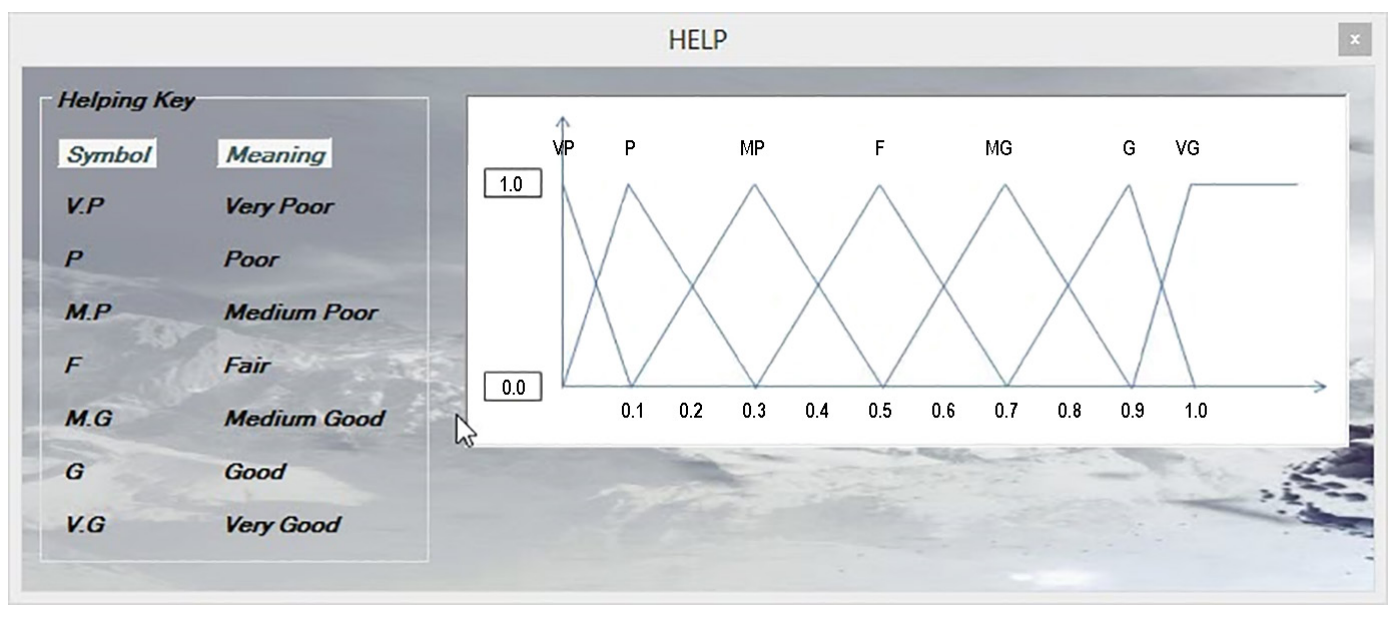

Figure 3. Fuzzy triangular membership functions "7" levels

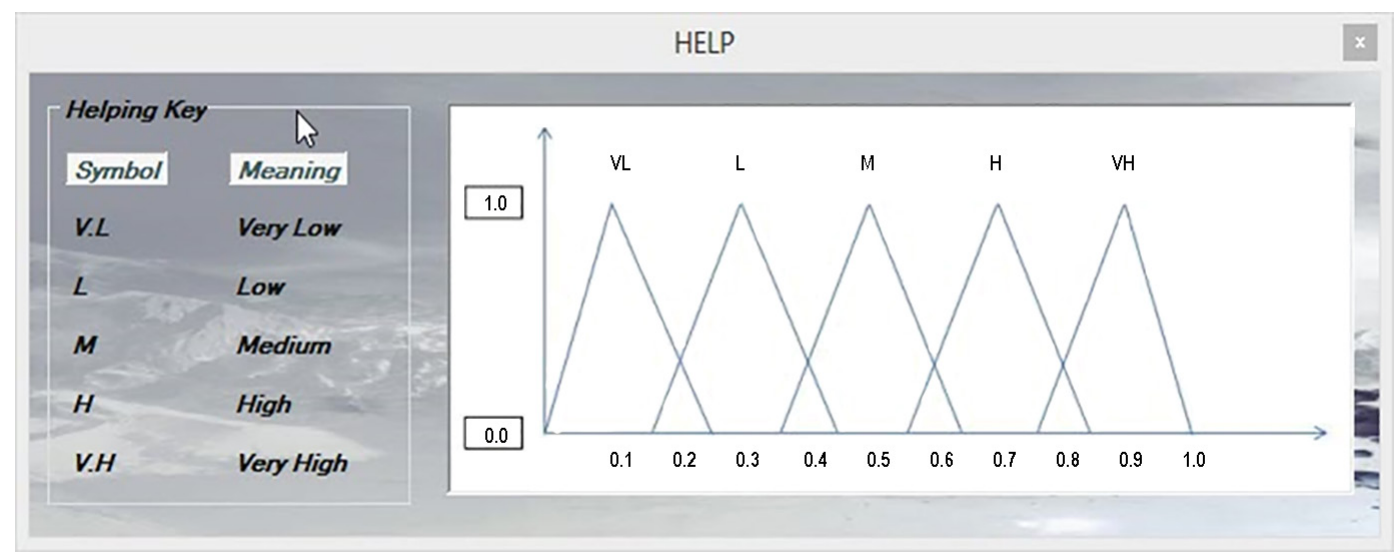

Figure 4. Fuzzy triangular membership functions "5" levels 
Next, decision makers start establishing the fuzzy decision matrix using linguistic variables to assess the alternatives according to the decision criteria. The linguistic variables range from very poor to very good (Issa \& Ahmed, 2014; Özat, 2013), TFNs "7" levels, as shown in Figure 3 or from very low to very high (Torfi \& Rashidi, 2011), TFNs " 5 " levels, as shown in Figure 4.

The decision makers identify whether the criteria or the sub-criteria are regarded as PISs $\left(v_{i}^{+}\right)$or NISs $\left(v_{i}^{-}\right)$. Their triangular fuzzy values are shown in Eqns (10) and (11).

$$
\begin{aligned}
& v_{i}^{+}=(1.0,1.0,1.0) ; \\
& v_{i}^{-}=(0.0,0.0,0.0),
\end{aligned}
$$

where: $v_{i}^{+}-$is the positive-ideal solution; $v_{i}^{-}-$is the negative ideal solution.

Then the model calculates the distance of each alternative from $v_{i}^{+}$and $v_{i}^{-}$using Eqns (12) and (13):

$$
\begin{aligned}
& D_{j}^{+}=\sum_{j=1}^{n} d\left(v_{i j}, v_{i}^{+}\right) ; \\
& D_{j}^{-}=\sum_{j=1}^{n} d\left(v_{i j}, v_{i}^{-}\right),
\end{aligned}
$$

where: $D_{j}^{+}-$is the distance to the PISs; $D_{j}^{-}-$is the distance to the NISs.

Finally, the alternatives are ranked according to Closeness Coefficient value $\left(C C_{j}\right)$ using Eqn (14):

$$
C C_{j}=\frac{D_{j}^{-}}{D_{j}^{+}+D_{j}^{-}},
$$

where $C C_{j}-$ is the Closeness Coefficient value.

\section{Verification of the MCDMM}

At this stage, it is essential to make sure that the model, and its two modules, achieves all the desired goals. For this purpose, the data from two real case studies are used to compare the achieved results and results from the model. Furthermore, the proposed model is validated in order to check the system for meeting the customer's actual needs.

\subsection{Verification of module (1)}

The problem of choosing the most suitable contractor is discussed by Al-Harbi (2001) and AHP technique is applied to solve it. The study specified six criteria affecting the process of ranking the different contractors including: experience, financial stability, quality performance, manpower resources, equipment resources, and current workload. The study compared among five available contractors $\mathrm{A}, \mathrm{B}, \mathrm{C}, \mathrm{D}$, and $\mathrm{E}$.

The MCDMM, applying module (1), compares the defined alternatives and the final ranking order of the alternatives is the same calculated by Al-Harbi (2001). The alternatives ranking order is $\mathrm{D}, \mathrm{C}, \mathrm{A}, \mathrm{B}$, and $\mathrm{E}$ with priority percentage of $28.8 \%, 24.1 \%, 22.2 \%, 20,1 \%$, and $4.6 \%$, respectively.

\subsection{Verification of module (2)}

Awasthi and Chauhan (2012) introduced city logistics initiatives which are steps taken by local administrators in order to enhance the condition of goods transport in cities. Four initiatives are considered, based on stakeholder opinion, namely vehicle sizing restrictions $\left(A_{1}\right)$, congestion charging schemes $\left(A_{2}\right)$, urban distribution center $\left(A_{3}\right)$, and access timing restrictions $\left(A_{4}\right)$. The DM group members identified four criteria and 16 factors affecting them.

By comparing the values of the four alternatives calculated by Awasthi and Chauhan (2012) and module (2) of the MCDMM; the same ranking for the alternatives is determined as: $A_{4}>A_{2}>A_{1}>A_{3}$. Therefore, alternative $A_{4}$ (Timing Restrictions) is selected as the sustainable city logistics initiative and recommended for implementation.

\section{Fuzzy simulation techniques in construction projects}

Fuzzy logic has overcome several limitations of simulation techniques in construction projects such as problems of uncertainty and lack of historical or documented data (Sadeghi, Fayek, \& Seresht, 2015; Mohammad, Nima, \& Aminah, 2016). Based on integrating with fuzzy logic, three main simulation techniques have been modified to be applied in construction projects. First technique is Fuzzy Discrete Event Simulation, which is widely used for modeling process-type construction tasks based on repetitions of similar activities. Second technique is Fuzzy System Dynamics, which allows construction planners to examine different strategies for project execution and perceive the effects of changing strategies on the system variables. Third technique is Fuzzy Agent-Based Modeling in which the modeler needs to define the individual's behavior. Consequently, global behavior of the system emerges as a result of many individuals following their own behavioral rules (Borshchev \& Filippov, 2004). Due to the fact that the Fuzzy Agent-Based Modeling technique emphasizes on problems investigation with cognitive uncertainty and systems whose behaviors are strongly influenced by human judgment, perception, or emotions, it is considered the best one that coincides the proposed model in this research.

\section{Selecting the best surveying technique applied to solar energy projects at Saudi Arabia}

Saudi Arabia, one of the Gulf Arab states, which was built on exporting crude oil, is predicting that fossil fuels will become a thing of the past by 2050 (Almasoud \& Gandayh, 2015). The increasing consumption of energy, the continuous decrease in existing sources of fossil fuels and the growing concern regarding environmental pollution, have motivated human to explore new technologies for producing electrical energy using clean, renewable sources such as solar energy, wind energy, etc. Among the nonconventional, renewable energy sources, solar energy affords the increasing potential for conversion into electric 


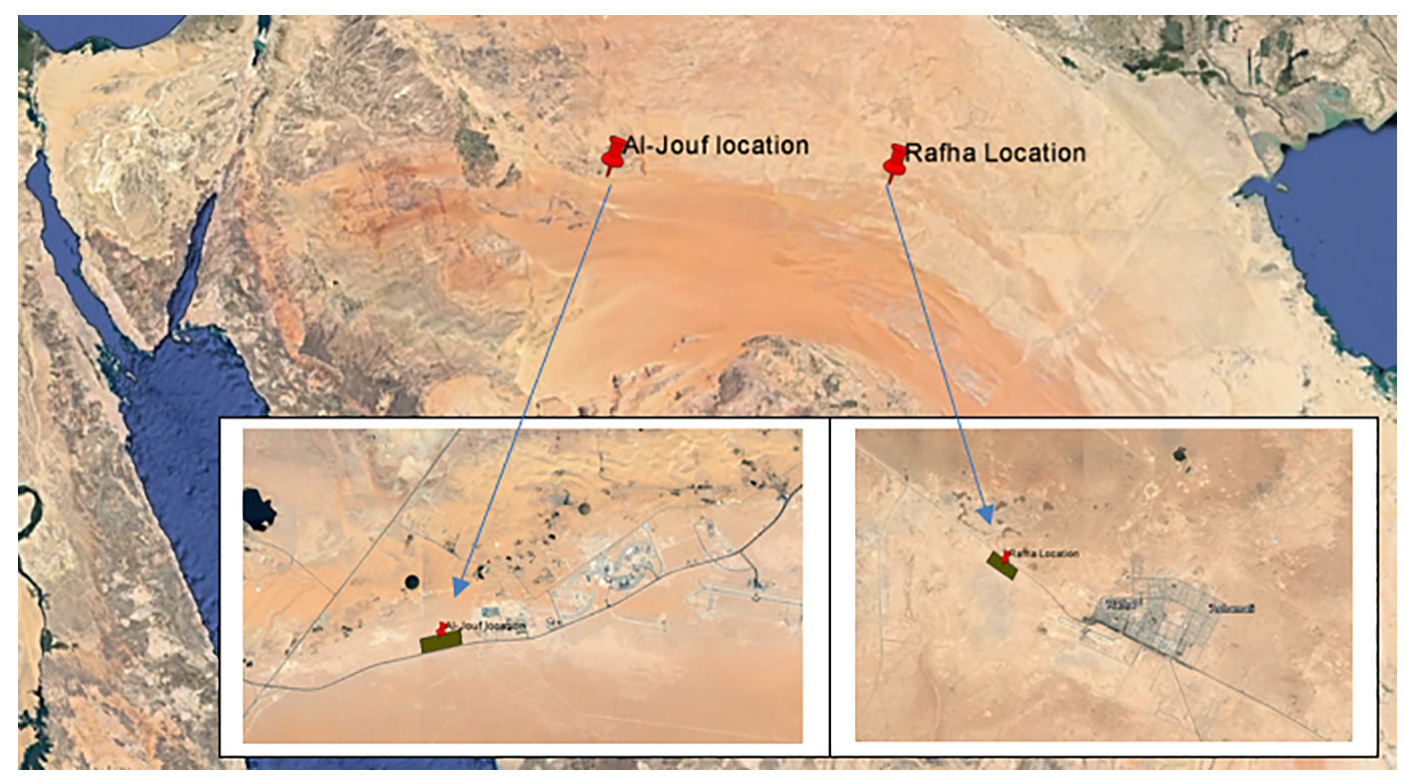

Figure 5. Location of both investigated projects

power, able to ensure an important part of the electrical energy needs of the planet.

\subsection{Case study description}

In 2016, Saudi Electricity Company (SEC) decided to execute two solar Photo Voltaic (PV) projects up to $50 \mathrm{MW}$ of PV capacities for each project. The location of these projects is in the northern region of the country, in AlJouf and Rafha, as shown in Figure 5. Each project covers an approximate area of two $\mathrm{km}^{2}$ with a total budget between USD 100 to 120 million. At the projects planning stage, it is important to produce a DTM.

The first step for estimating DTM is to collect data, which is a digital representation of the elevation of the ground. This model may be considered as a representation of the raw information regarding the elevation of the Terrain (Duguay, 1993). In surveying, more sophisticated instruments and methodologies might be employed (i.e. Traditional Surveying Techniques, GPS, Airborne laser scanning (LIDER), Arial photogrammetry, Synthetic Aperture Radar (SAR) Interferometry, RS, and Cartographic Digitization) to collect data for DTM generation.

\subsection{Data collection strategy}

The brainstorming technique is considered one of the most common identification techniques for gathering data in CEPs. It has been recently applied in KSA construction industry by many researchers such as Issa and Salama (2018), Mosaad, Issa, and Hassan (2018). To achieve the research objectives, an elementary session reviewing the characteristics of the project and two brainstorming sessions are held at Department of Geomatics, King AbdulAziz University, and SEC. These sessions were carried out with surveying professors, solar energy specialists, representatives of SEC and project managers, with practical experiences in executing and supervising these types of projects. The first brainstorming session is conducted to identify surveying techniques to be applied in building up the DTM. The second brainstorming session will be explained later in the Model Application section.

As a result from the first session, four surveying techniques are picked up to select from them. Four alternatives are conventional surveying methodologies (using Total Station (TS)), Global Positioning Systems (GPS), Photogrammetry, and Remote Sensing (RS). Also, five criteria and twelve factors affecting them were identified and become the theoretical foundation for the research. Table 2 shows the identified five criteria and factors affecting them.

\subsection{Projects' characteristics and circumstances}

Before the brainstorming sessions are held, all information and data relevant to the projects are reviewed to clarify the characteristics of the DTM problem and make an overall

Table 2. Brief description of the identified five criteria and factors affecting them

\begin{tabular}{|l|l|}
\hline Saving in costs $\left(\boldsymbol{C}_{\mathbf{1}}\right)$ & Saving execution cost (SC11) \\
\cline { 2 - 2 } & Saving instruments cost (SC12) \\
\hline Ease of use $\left(\boldsymbol{C}_{\mathbf{2}}\right)$ & $\begin{array}{l}\text { No need for administrative approvals } \\
(\text { SC21) }\end{array}$ \\
\cline { 2 - 2 } & Ease of field works (SC22) \\
\cline { 2 - 2 } & Ease of topography (SC23) \\
\hline \multirow{3}{*}{ Rate of capture $\left(\boldsymbol{C}_{\mathbf{3}}\right)$} & Skilled manpower availability (SC31) \\
\cline { 2 - 2 } & Geology and soil type (SC32) \\
\cline { 2 - 2 } & Climatic conditions (SC33) \\
\hline Applicability $\left(\boldsymbol{C}_{\mathbf{4}}\right)$ & Availability of instruments (SC41) \\
\cline { 2 - 2 } & Limitation of execution time (SC42) \\
\hline \multirow{2}{*}{ Quality of data $\left(\boldsymbol{C}_{5}\right)$} & Distribution of Data (SC51) \\
\cline { 2 - 2 } & Availability of special crews (SC52) \\
\hline
\end{tabular}


view of the objectives of the upcoming sessions. All data regarding temperature, wind and solar energy distribution were obtained from the weather stations located in Al-Jouf domestic airport and Rafha domestic airport. That information plays a vital role in choosing the suitable alternatives and the factors affecting the ranking process among them. The main points reviewed in this session summarized as follow:

\section{Geology and topography of the projects area}

Yellow hard sand and thin layers of sandstone cover the area of the Al-Jouf and Rafha projects. The surface at the site is probably stable enough for surveying works and for the construction of the panel arrays. In addition, the topography of the project area of Al-Jouf and Rafha are mainly flat, with a maximum elevation change of $25 \mathrm{~m}$ and $29 \mathrm{~m}$ respectively, and an average elevation above sea level of $670 \mathrm{~m} 446 \mathrm{~m}$, respectively.

\section{Temperature}

Extreme temperatures have obvious physical effects on laborers. In addition, Survey equipment has, like most other electro/mechanical devices, usable operating temperatures specified by extreme values. Furthermore, batteries are very susceptible to extreme temperatures.

Al-Jouf and Rafha have a hot desert climate. The temperature typically varies from $40^{\circ} \mathrm{F}$ to $105^{\circ} \mathrm{F}$ over the course of the year and is rarely below $33^{\circ} \mathrm{F}$ or above $111^{\circ} \mathrm{F}$. Average High and Low Temperatures of Al-Jouf and Rafha locations are shown in Figures 6-7.

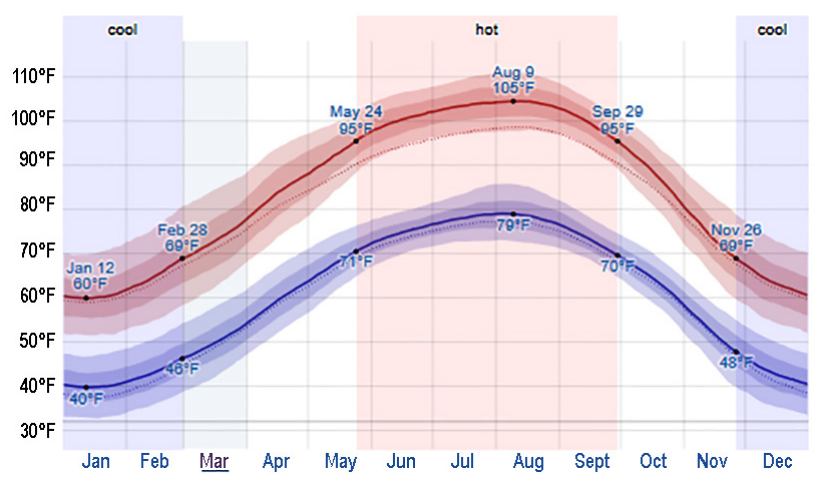

Figure 6. Average high and low temperature of Al-Jouf location

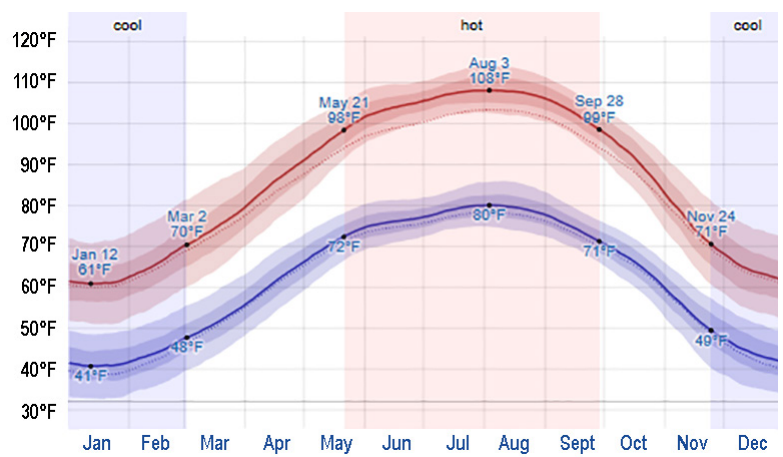

Figure 7. Average high and low temperature of Rafha location

\section{Wind speed}

The Wind creates its own trouble. Not only it intensifies temperatures, but also it decreases the stability of surveying equipment. It is almost impossible to hold a prism pole plumb with gusting winds. Too much wind and, as an example, the total station can become unleveled. The average of mean hourly wind speeds measured at Al-Jouf and Rafha range from 4 to $5 \mathrm{mph}$.

\section{Solar energy distribution}

Solar energy distribution discusses the total daily incident shortwave solar energy reaching the surface of the ground over a wide area, taking full account of seasonal variations in the length of the day, the elevation of the sun above the horizon, absorption by clouds, and other atmospheric constituents. The average daily shortwave solar energy reaching the ground per square meter over Al-Jouf and Rafha locations are illustrated in Figures 8-9.

\subsection{Model application}

Both the two modules in the MCDMM are suggested to be applied in this project due to the availability of the required data. Therefore, two results can be identified due to different techniques. In addition, the two results can be compared, illustrated, and help to reach a certain, and precise decision. Then, the second brainstorming session is conducted to gather the data, which feed the model. This step was done by a question and answer session to make

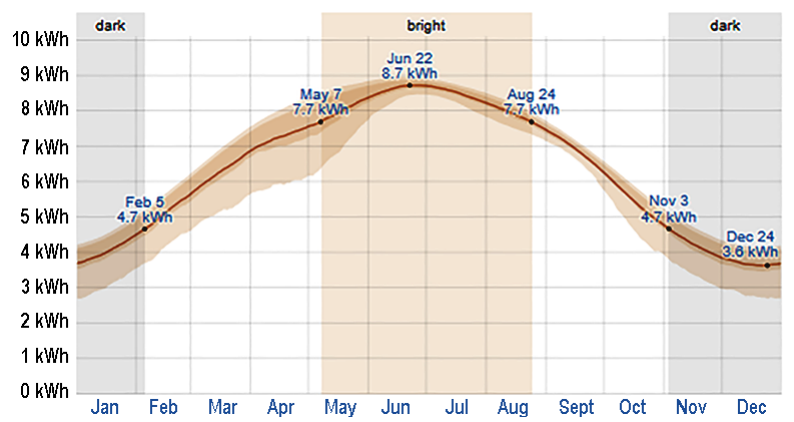

Figure 8 . The average daily shortwave solar energy reaching the ground per over Al-Jouf location

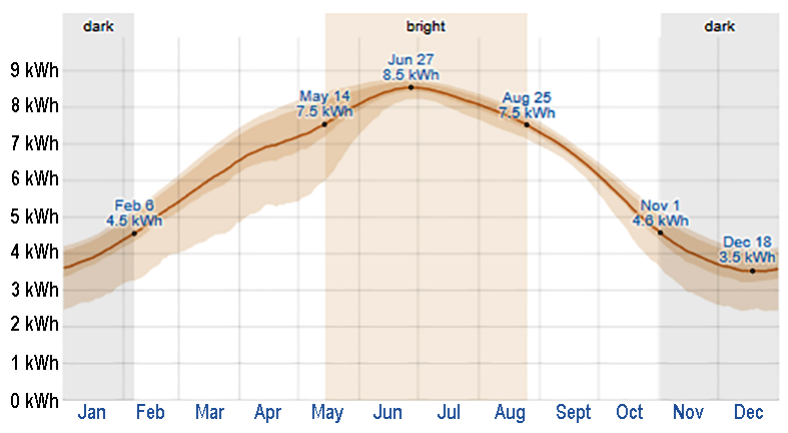

Figure 9. The average daily shortwave solar energy reaching the ground per over Rafha location 
sure that everyone fully understood each response. All attendees are informed by the objectives of the session for enhancing its efficiency. Several comparison matrices are introduced. The goal of the study is to support the choice for one of the available surveying techniques to be used in the investigated projects.

\section{Applying module (1)}

The decision makers feed the module with the values of pairwise comparison matrices of the five criteria, the module calculates the criteria relative weights, and checks on the value of consistency ratio as shown in Figure 10.

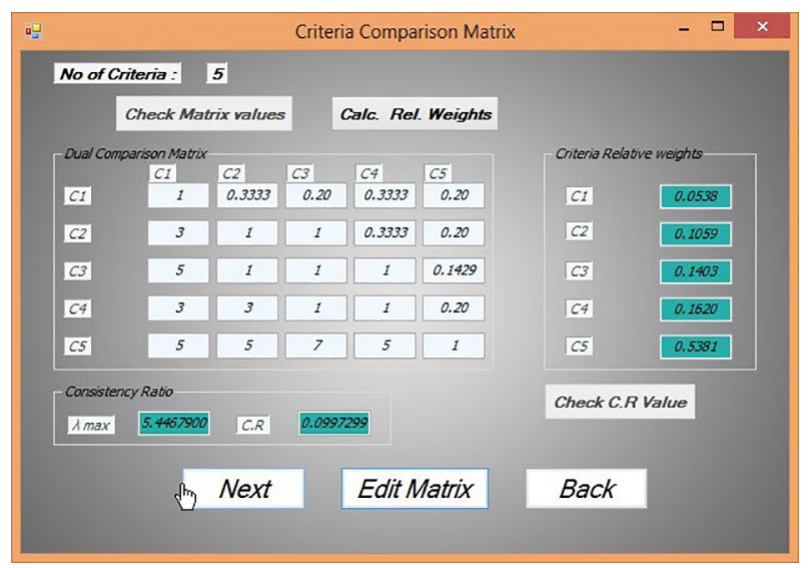

Figure 10. Criteria comparison matrix and their relative weights

Then, the decision makers start comparing among the alternatives based on satisfying one criterion each time. After that, the model calculates the preference value of each alternative based on the previous data provided by the decision makers.

As a result, TS is preferred mostly by $31.75 \%$, RS comes next by 27.56\%; at the last ranking order is Photogrammetry and GPS with only $22.39 \%$ and $18.32 \%$ respectively. The results can be shown as column chart to clarify the ranking order of alternatives as shown in Figure 11.

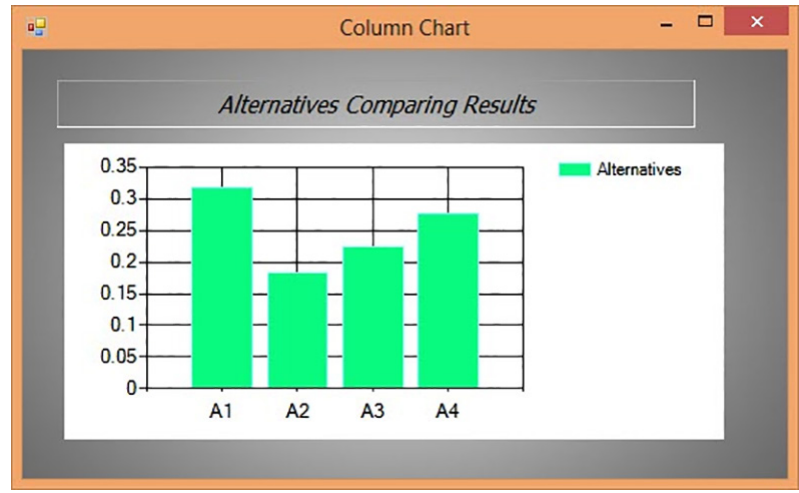

Figure 11. Alternatives ranking

\section{Applying module (2)}

At this stage, the research group applies the AHP and Fuzzy TOPSIS module to take into consideration the twelve factors affecting the defined criteria. Besides, getting benefits from using the linguistic variables to reduce the uncertainty of the provided data.

AHP is applied first to calculate the relative weights of all defined five criteria and twelve sub-criteria. $C R$ value is checked for each comparison matrix to not exceed 0.10. The DM group used TFNs "7" levels to widen the range of linguistic variables selection. After that, all alternatives are compared against the twelve factors affecting the problem. Linguistic variables are used through this stage as shown in Figure 12.

Finally, the cost criteria and the benefit criteria are identified and defined in the model. $C C_{j}$ is calculated for each alternative in order to rank them based on $C C_{j}$ values. The TS is preferred mostly with 0.3125 . After that, the remaining alternatives rank come next with convergent preferences of $0.2943,0.2955$, and 0.2972 , respectively.

\subsection{Sensitivity analysis}

In this section, a sensitivity analysis is provided for the considered case study to indicate effects of various weights

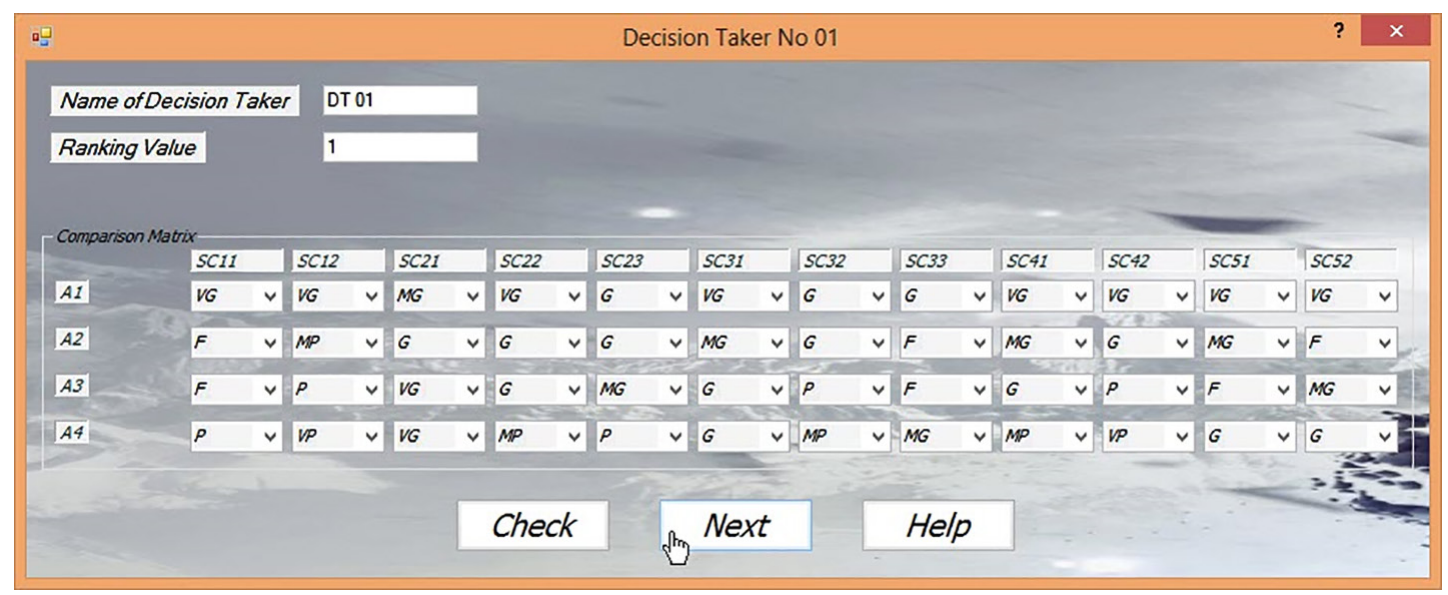

Figure 12. Linguistic variables for assessing the alternatives 
of the criteria on the obtained ranking results. For this purpose, the weight of each criterion is increased and considers small values for other criteria. The related results are provided in Table 3.

The ranking of surveying techniques alternatives are not changed by increasing weights of saving in cost $\left(C_{1}\right)$ and Ease of use $\left(C_{2}\right)$ criteria which leads to the same ranking results as below:

$$
A_{1}>A_{2}>A_{3}>A_{4} \text {. }
$$

On the other hand, Rate of capture $\left(C_{3}\right)$, Applicability $\left(C_{4}\right)$, and Quality of data $\left(C_{5}\right)$ are more impressive for the ranking order of surveying techniques alternatives.

Furthermore, the most preferable alterative still the same even if change occurs in weights of $C_{1}, C_{2}$, and $C_{5}$. Conversely, any change in $C_{3}$ and $C_{4}$ leads to totally change of the alternative ranking order.

Table 3. Sensitivity analysis for effects of different weights of the criteria on ranking results

\begin{tabular}{|c|c|c|c|c|c|c|}
\hline \multirow{2}{*}{\multicolumn{2}{|c|}{ Criteria }} & \multicolumn{5}{|c|}{ Criteria Weights } \\
\hline & & State 1 & State 2 & State 3 & State 4 & State 5 \\
\hline$C_{1}$ & & 0.96 & 0.01 & 0.01 & 0.01 & 0.01 \\
\hline$C_{2}$ & & 0.01 & 0.96 & 0.01 & 0.01 & 0.01 \\
\hline$C_{3}$ & & 0.01 & 0.01 & 0.96 & 0.01 & 0.01 \\
\hline$C_{4}$ & & 0.01 & 0.01 & 0.01 & 0.96 & 0.01 \\
\hline$C_{5}$ & & 0.01 & 0.01 & 0.01 & 0.01 & 0.96 \\
\hline \multirow{4}{*}{ 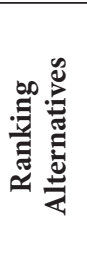 } & $1^{\text {st }}$ & $A_{1}$ & $A_{1}$ & $A_{3}$ & $A_{3}$ & $A_{1}$ \\
\hline & $2^{\mathrm{nd}}$ & $A_{2}$ & $A_{2}$ & $A_{4}$ & $A_{1}$ & $A_{4}$ \\
\hline & $3^{\text {rd }}$ & $A_{3}$ & $A_{3}$ & $A_{2}$ & $A_{2}$ & $A_{2}$ \\
\hline & $4^{\text {th }}$ & $A_{4}$ & $A_{4}$ & $A_{1}$ & $A_{4}$ & $A_{3}$ \\
\hline
\end{tabular}

\subsection{Discussion and analysis}

Four surveying techniques are picked up to select from them to be used conducting the DTM. Four alternatives are TS, GPS, Photogrammetry, and RS. The research regarded the two projects as one due to the same features of them regarding the discussed DM problem. Specifically, the topography of the site, temperature, and wind speed rates. In addition, five criteria and twelve factors affecting them were identified and become the theoretical foundation for the research.

The first criterion is saving in cost due to applying one technique instead of another. Saving cost includes execution costs and instruments costs. In fact, due to the available budget for the projects, the saving cost criterion has a little priority as found by the decision makers.

Ease of use criteria is answering the question of how much applying one technique is easier compared with others. Three main inquiries are answered as results of comparison matrix of this criterion. The first aspect is the need for administrative approvals to apply each technique. The second question is how much easy to apply each technique in the field compared to others. At last, easy of topography is illustrating the ability of techniques to be used in different site topographies.

Both the rate of capture and Applicability criteria are regarded with approximately the same priority. The rate of capture is concerned with the period needed to finish this work depending on the used technique. The time needed to conduct the DTM is depending on different factors including manpower availability, soil type on the site of the project, and climate conditions surrounding the projects. While, applicability is looking to answer the questions of the availability of the instrument of each technique and the limitations of execution time, if found, for each type of instrument.

Conversely, the fifth criterion, quality of data, is regarded as the major factor in this problem due to the importance of producing data with high quality to ensure the success of this high technology projects. This factor is concerned about the quality of the produced data to simulate the real case with minor errors not affecting the incoming process. In order to provide such high-quality data, two trends need to be observed and satisfied. The first is to make sure that there are skilled crews to conduct such works. The other is the need of well-planned distribution of data to provide accurate results.

A final decision, using the TS as a surveying instrument in conducting the DTM, is delivered to the project participants. TS is preferred mostly because of the high quality of data delivered, the availability of skilled crews working with TS, and finally providing well-planned distribution of data.

\section{Conclusions and recommendations}

CEPs, with all their aspects, face the problem of making a decision to pick up the best alternative from a set, based on various criteria and factors affecting the process. Therefore, this work develops a MCDMM to increase the flexibility, reduce the uncertainty, and deal with wide range of data related to CEPs. The proposed model utilizes Visual Studio Program package as the main programming tool and consists of two modules; module (1) uses AHP only, while module (2) combines AHP and Fuzzy TOPSIS. Two real case studies are illustrated in order to verify the model. Furthermore, MCDMM is applied to prioritize among four surveying techniques for selecting the most suitable one to conduct the DTM for solar energy projects in Saudi Arabia. Five criteria and twelve factors affecting them were identified including: Saving in cost, Ease of use, Rate of capture, Applicability, and Quality of data. In addition, a sensitivity analysis has been prepared to present effects of changing the criteria weights on the ranking results.

Based on the results of model characteristics and application on the investigated case study, the main conclusions can be summarized as follows: 
1. MCDMM deals with various data types whether precise intangible qualitative beside tangible quantitative data or vague data from field surveys.

2. MCDMM improves the uncertainty of the gathered data by taking into consideration more than one weighted source related to the discussed problem.

3. MCDMM adopts two different fuzzy membership functions, so it is easy to deal with a variety of data collection techniques.

4. The model results proved that applying T.S as a conventional surveying technique in this project is the most suitable alternative among the compared alternatives.

5. The model through applying the two modules, in the investigated case study, supported the use of T.S over passing RS, Photogrammetry, and GPS respectively.

6. Results obtained from the sensitivity analysis have indicated that ranking order of alternatives stay consistent even if weights of saving in cost and Ease of use criteria have been changed, while Rate of capture, Applicability, and Quality of data are more impressive for the ranking order.

7. Finally, the developed model in this study can be used sufficiently flexible in other study cases related to the CEPs.

For future work, other techniques can be considered for extending the AHP method under uncertainty such as IVHFS. Also, other modules can be easily added to widen the range of model application.

\section{Funding}

This research did not receive any specific grant from funding agencies in the public, commercial, or not-for-profit sectors.

\section{Disclosure statement}

Authors have no conflicts of interest to disclose.

\section{References}

Abdel-malak, F. F., Issa, U. H., Miky, Y. H., \& Osman, E. A. (2017). Applying decision-making techniques to civil engineering projects. Beni-Suef University Journal of Basic and Applied Sciences, 6(4), 326-331.

https://doi.org/10.1016/j.bjbas.2017.05.004

Albayrak, E., \& Erensal, Y. C. (2004). Using analytic hierarchy process (AHP) to improve human performance: An application of multiple criteria decision making problem. Journal of Intelligent Manufacturing, 15(4), 491-503.

https://doi.org/10.1023/B:JIMS.0000034112.00652.4c

Al-Harbi, K. M. A.-S. (2001). Application of the AHP in project management. International Journal of Project Management, 19(1), 19-27. https://doi.org/10.1016/S0263-7863(99)00038-1

Almasoud, A. H., \& Gandayh, H. M. (2015). Future of solar energy in Saudi Arabia. Journal of King Saud University Engineering Sciences, 27(2), 153-157.

https://doi.org/10.1016/j.jksues.2014.03.007
Alwetaishi, M., Gadi, M., \& Issa, U. H. (2017). Reliance of building energy in various climatic regions using multi criteria. International Journal of Sustainable Built Environment, 6(2), 555-564. https://doi.org/10.1016/j.ijsbe.2017.12.002

Awasthi, A., \& Chauhan, S. S. (2012). A hybrid approach integrating Affinity Diagram, AHP and fuzzy TOPSIS for sustainable city logistics planning. Applied Mathematical Modelling, 36(2), 573-584. https://doi.org/10.1016/j.apm.2011.07.033

Borshchev, A., \& Filippov, A. (2004). From system dynamics and discrete event to practical agent-based modeling: Reasons, techniques, tools. In Proceedings of the $22^{\text {nd }}$ International Conference of the System Dynamics Society, Oxford, England.

Bruno, G., Esposito, E., Genovese, A., \& Simpson, M. (2016). Applying supplier selection methodologies in a multi-stakeholder environment: A case study and a critical assessment. Expert Systems with Applications, 43, 271-285.

https://doi.org/10.1016/j.eswa.2015.07.016

Duguay, C. R. (1993). Radiation modeling in mountainous terrain - Review and status. Mountain Research and Development, 13(4), 339. https://doi.org/10.2307/3673761

Ebrahimnejad, S., Gitinavard, H., \& Sohrabvandi, S. (2017). A new extended Analytical Hierarchy Process technique with incomplete intervalvalued information for risk assessment in IT outsourcing. IJE Transactions B: Applications, 30(5), 739-748.

El Chanati, H., El-Abbasy, M. S., Mosleh, F., \& Senouci, A. (2016). Multi-criteria decision making models for water pipelines. Journal of Performance of Constructed Facilities, 30(4), 04015090 . https://doi.org/10.1061/(ASCE)CF.1943-5509.0000842

Erdoğan, M., \& Kaya, İ. (2016). A combined fuzzy approach to determine the best region for a nuclear power plant in Turkey. Applied Soft Computing, 39, 84-93. https://doi.org/10.1016/j.asoc.2015.11.013

Forman, E. H., \& Selly, M. A. (2001). Decision by objectives. How to convince others that you are right. World Scientific. https://doi.org/10.1142/4281

Gitinavard, H., Pishvaee, M. S., \& Jalalvand, F. (2017). A hierarchical multi-criteria group decision-making method based on TOPSIS and hesitant fuzzy information. International Journal of Applied Decision Sciences, 10(3), 213.

https://doi.org/10.1504/IJADS.2017.085084

Hassan, A., \& Issa, U. H. (2015). Developing a decision-making model for reinforced concrete columns strengthening. International Journal of GEOMATE, 9(1), 1333-1341. https://doi.org/10.21660/2015.17.77814

Issa, U. H., \& Ahmed, A. (2014). On the quality of driven piles construction based on risk analysis. International Journal of Civil Engineering, 12(2), 121-129.

Issa, U. H., \& Salama, I. M. (2018). Improving productivity in Saudi Arabian construction projects: An analysis based on Lean techniques. International Journal of Applied Engineering Research, 13(10), 8669-8678.

Jahan, A., Edwards, K. L., \& Bahraminasab, M. (2016). Multicriteria decision analysis for supporting the selection of engineering materials in product design ( $2^{\text {nd }}$ ed.). ButterworthHeinemann.

Karahalios, H. (2017). The application of the AHP-TOPSIS for evaluating ballast water treatment systems by ship operators. Transportation Research Part D: Transport and Environment, 52(Part A), 172-184. https://doi.org/10.1016/j.trd.2017.03.001

Mohammad, R., Nima, G. S., \& Aminah, R. F. (2016). Overview of Fuzzy simulation techniques in construction engineering and management. In Annual Conference of the North Ameri- 
can Fuzzy Information Processing Society (NAFIPS), El Paso, TX, USA. https://doi.org/10.1109/NAFIPS.2016.7851610

Mosaad, S. A. A., Issa, U. H., \& Hassan, M. S. (2018). Risks affecting the delivery of HVAC systems: Identifying and analysis. Journal of Building Engineering, 16, 20-30. https://doi.org/10.1016/j.jobe.2017.12.004

Mousavi, S., Gitinavard, H., \& Siadat, A. (2014). A new hesitant fuzzy analytical hierarchy process method for decision-making problems under uncertainty. In IEEE International Conference on Industrial Engineering and Engineering Management (IEEM) (pp. 622-626). Bandar Sunway, Malaysia.

Özat, S. T. (2013). Determination of criterion that affects supplier selection in public administration software tenders and selection of supplier (Doctoral dissertation, Çankaya University).

Pacheco, F., Cerrada, M., Sánchez, R.-V., Cabrera, D., Li, C., \& de Oliveira, J. V. (2017). Attribute clustering using rough set theory for feature selection in fault severity classification of rotating machinery. Expert Systems with Applications, 71, 69-86. https://doi.org/10.1016/j.eswa.2016.11.024

Plebankiewicz, E., \& Kubek, D. (2016). Multicriteria selection of the building material supplier using AHP and Fuzzy AHP. Journal of Construction Engineering and Management, 142(1), 04015057.

https://doi.org/10.1061/(ASCE)CO.1943-7862.0001033

Saaty, T. L. (1980). The analytic hierarchy process. New York: McGraw-Hill.

Sadeghi, N., Fayek, A. R., \& Seresht, N. G. (2015). Queue performance measures in construction simulation models contain- ing subjective uncertainty. Automation in Construction, 60, 1-11. https://doi.org/10.1016/j.autcon.2015.07.023

Samuel, O. W., Asogbon, G. M., Sangaiah, A. K., Fang, P., \& Li, G. (2017). An integrated decision support system based on ANN and Fuzzy_AHP for heart failure risk prediction. Expert Systems with Applications, 68, 163-172. https://doi.org/10.1016/j.eswa.2016.10.020

Tavakkoli-Moghaddam, R., Gitinavard, H., Mousavi, S. M., \& Siadat, S. (2015). An interval-valued hesitant fuzzy TOPSIS method to determine the criteria weights. In International Conference on Group Decision and Negotiation GDN 2015: Outlooks and Insights on Group Decision and Negotiation, Lecture Notes in Business Information Processing (pp. 157-169). Springer. https://doi.org/10.1007/978-3-319-19515-5_13

Torfi, F., \& Rashidi, A. (2011). Selection of project managers in construction firms using Analytic Hierarchy Process (AHP) and Fuzzy Topsis: A case study. Journal of Construction in Developing Countries, 16(1), 69-89.

Wang, Y.-J., \& Lee, H.-S. (2007). Generalizing TOPSIS for fuzzy multiple-criteria group decision-making. Computers \& Mathematics with Applications, 53(11), 1762-1772. https://doi.org/10.1016/j.camwa.2006.08.037

Zyoud, S. H., Kaufmann, L. G., Shaheen, H., Samhan, S., \& FuchsHanusch, D. (2016). A framework for water loss management in developing countries under fuzzy environment: Integration of Fuzzy AHP with Fuzzy TOPSIS. Expert Systems with Applications, 61, 86-105. https://doi.org/10.1016/j.eswa.2016.05.016 